\title{
De ocupantes a propietarios, los conflictos entre vecinos de la frontera bonaerense. Chascomús y Ranchos, 1800-1840.'
}

\section{Guillermo Banzato ${ }^{2}$}

La conflictos en la sociedad rural rioplatense, que hasta no hace mucho estaban relegados en los estudios sobre el mundo rural, ha sido abordados últimamente. A los trabajos de Pilar González Bernaldo quien retomando el antiguo tema del conflicto político en la época de Rosas estudia con una mirada renovadora la Rebelión del Sur ${ }^{3}$ y de Ricardo Salvatore sobre la reacciones de los habitantes de la campaña a la coerción estatal y la presión del mercado de trabajo, ${ }^{4}$ se han sumado los de Juan Carlos Garavaglia, que miran el conflicto social analizando "las representaciones sociales", las "formas de solidaridad" y las tensiones en torno al ceremonial, tanto como las disputas políticas en el nivel local. ${ }^{5}$ En esta perspectiva, que intenta desentrañar las continuidades y rupturas entre el orden colonial y el entramado político y social del rosismo,

1-Versiones preliminares de este trabajo fueron presentadas al III Encuentro Argentino-Chileno de Estudios Históricos, Buenos Aires 15, 16 y 17 de abril de 1999 y al seminario "Relaciones interétnicas y vida cotidiana en la Araucanía y la frontera pampeana (siglos XVI a XVIII)" dictado por el Dr. Carlos Mayo en el Programa de Doctorado en Historia de la UNLP. Agradezco la lectura crítica de Marta Valencia y Alicia Lorenzo, como así tambíen las indicaciones del evaluador de la revista.

2-Centro de Estudios Histórico-Rurales. Universidad Nacional de La Plata.

3-González Bernaldo (1987).

4-Salvatore (1992) y (1993).

5-Garavaglia (1999). 
nuestra intención es aportar un análisis sobre los litigios entre vecinos cuando la posesión de hecho sobre un terreno estaba en vías de convertirse en propiedad plena, cada vez que se accedía a los títulos mediante los distintos sistemas de otorgamiento de tierras públicas, desde los últimos años del período colonial hasta la finalización de la aplicación de la enfiteusis en la década de 1840, centrando la atención en la ocupación del territorio y los derechos adquiridos en los partidos de Chascomús y Ranchos. Aquí se pone de manifiesto el reconocimiento local de los estancieros y hacendados y los motivos de las disputas. A partir del análisis de los litigios se aprecia el juego de intereses de los hacendados y las conexiones con el poder civil en la frontera que se definen en la resolución extrajudicial del conflicto. Por otro lado se examinará el rol de las autoridades y los fundamentos de los dictámenes. Se revisarán los motivos de los conflictos y los razonamientos que expusieron las partes, argumentos que, si bien no siempre salen de la pluma del directamente implicado, es posible decir que éste aporta los ejes principales y, por otro lado, si no sabe escribir le es leído por el letrado que lo representa. De manera que, análogamente al caso de los documentos de la justicia civil, en estos también es posible escuchar las voces de los distintos sectores que componen la compleja y cambiante sociedad rural decimonónica. ${ }^{6}$ Entre los motivos de los litigios se distingue especialmente el reconocimiento de antigua posesión, además se presentan los que apuntan a la prelación en la denuncia del terreno, los que pretenden hacer valer los servicios militares y los que apelan a la necesidad de contar con un espacio mínimo a partir del cual llevar adelante un establecimiento productivo. Lógicamente, hay que tener en cuenta que difícilmente se encuentran aislados, uno, dos o todos juntos se relacionan en una misma exposición, o a lo largo de sucesivas solicitudes y, a la vez, están en tensión, pues un litigante utiliza uno de estos argumentos para contraponerlo con otro que ha usado su adversario. En conjunto, ilustran acerca de la utilización de la legislación y la permanencia de normas consuetudinarias,? por lo tanto se verá cómo la antigua posesión estuvo cada vez más comprometida como figura jurídica precaria, a medida que las nuevas leyes y decretos fueron condicionando la adjudicación de títulos de tierras públicas, especialmente los relacionados con la enfiteusis, aunque mantuvo durante todo el período una importancia fundamental.

Los pagos de Chascomús y Ranchos fueron la primera avanzada militar y

6-En este sentido seguimos las reflexiones que sobre el problema de las fuentes judiciales han realizado Mayo et. al. (1989)..

7-Cfr. Fradkin (1997). 
productiva que la estrategia colonial estableció durante el virreinato de Vértiz, con el fin de aumentar la extensión de las tierras productivas y al mismo tiempo defender el territorio durante los períodos de guerra con las tribus aborígenes. ${ }^{8}$ Desde fines de la década de 1770 , en un radio de alrededor de 100 kilómetros de Buenos Aires, comenzaron a levantarse fuertes y fortines a lo largo del río Salado, límite natural de muy escasa efectividad a la hora de detener los malones, pero indispensable como aguada permanente para los animales. Esta línea de establecimientos militares y productivos se iniciaba precisamente con el fuerte de Chascomús y seguía hacia el nordeste con Ranchos, ambos enmarcados por la confluencia de los ríos Salado y Samborombón. Hacia el noroeste continuaban Monte, Lobos, Navarro y Guardia de Luján. De esta manera en las últimas décadas del siglo XVIII, a partir de la limitada protección que brindaba la nueva línea de fronteras, el área bonaerense fue ocupándose con una lenta pero constante marcha de familias y hombres solos, mieses y ganados, traspasando el delgado límite que ofrecía el río Salado y presionando hacia el interior del territorio aborigen. ${ }^{9}$ La instalación de los primeros pobladores en terrenos baldíos que se consideraban con derechos a la posesión de la tierra realenga se vio amenazada cuando a principios del siglo XIX debido a las migraciones internas, se asentaron sobre el territorio fronterizo nuevos ocupantes, multiplicando el escaso vecindario original en un espacio que, aún así, resultaba lo suficientemente vasto como para contenerlos. ${ }^{10} \mathrm{Hacia}$ la década de 1830 Chascomús y Ranchos declinaron como avanzada militar, pues el constante avance de la frontera había trasladado la función de defensa a los fuertes que se levantaban al sur y el oeste de la provincia, " aunque continuaba la llegada de pobladores, a la vez que el funcionamiento de un incipiente mercado de tierras provocaba un cambio en las cohortes de propietarios.

Con el sistema colonial de entrega de tierras en moderada composición, que también utilizaron los primeros gobiernos posrevolucionarios, los solicitantes de terrenos realengos debían confirmar su antigüedad de posesión con la declaración de tres testigos. ${ }^{12}$ En otro trabajo hemos observado que cuando el asentamiento superaba los diez años el ocupante tenía preferencia en la venta, en caso contrario se sacaba a remate. ${ }^{13}$ Sin embargo, en ciertas ocasiones, la ocupación sin títulos, el atraso de los expedientes o la deficiencia en las men-

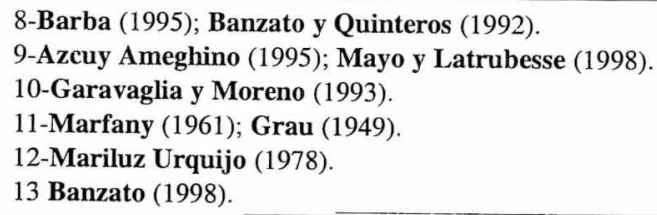


suras, provocaron disputas entre quienes consideraban que tenían mejores derechos para aspirar al título sobre la tierra. Hacia 1816, al mismo tiempo que se mantenía el sistema anterior, el Director Supremo Álvarez Thomas se propuso ampliar la frontera interior, ${ }^{14}$ una vez realizadas las expediciones correspondientes se decidió no avanzar más allá de la laguna Kaquelhuincul, pues hasta esa zona se habían encontrado establecimientos ganaderos. ${ }^{15}$ En función de consolidar esta línea de frontera y de reforzar las buenas relaciones que se habían establecido con los aborígenes, se pretendía poblar el territorio, en una política que estaba en la misma línea de la emprendida por el virrey Vértiz cuarenta años antes. Para ello se decidió conceder tierras en donación a quienes estuvieran interesados en criar ganados o cultivar, con la sola condición de que fundaran estancias en el plazo de cuatro meses y auxiliaran en la defensa militar de la frontera. ${ }^{16}$ La legislación acerca de la enfiteusis alcanzó unos cuarenta decretos y leyes que intentaban reglar sobre la marcha la entrega en usufructo de las tierras públicas. Este sistema se aplicó mayoritariamente en los nuevos territorios de la frontera sur, aunque también al norte del río Salado se adjudicaron algunos terrenos. ${ }^{17}$

En la zona que aquí se estudia, los trámites para la obtención del título fueron realizados muy posteriormente al asentamiento, especialmente en el período $1818-1822 .^{18}$ De las 50 parcelas obtenidas en moderada composición 24 tenían más de diez años de ocupación, aunque no hubo posturas en contrario en la gran mayoría de los que tenían menos, o el ocupante ganó en la puja. Claro que, al levantar un rancho, hacer un corral y aquerenciar los animales, ya se ganaba, ante la comunidad, el privilegio de primer ocupante aunque mediara escaso tiempo con la denuncia. ${ }^{19}$ Tal como reconocía un fiscal en 1803 al oponerse a una solicitud de asentamiento, debido a que

"quando se hubiesen de sacar a remate esas tierras, hallandose ocupadas y pobladas no habria otros que quisiesen hacer postura, ya por contemplacion al posedor, y ya por no entrar despues en litigios con el sobre lo edificado y plantado, sino les acomoda su compra, ó sobre la saca de Ganados que dificilmente pierden la querencia... ${ }^{20}$

14-Decreto del 11 de marzo de 1816. REGISTRO OFICIAL DE LA REPÚBLICA ARGENTINA, Buenos Aires, Imprenta especial de obras, 1879, v. 1, p. 352. (En adelante RORA)

15-Infesta (1986).

16-Decreto del 15 de noviembre de 1818. RORA, v. 1, p. 480.

17-Para un análisis de la legislación y estudio cuantitativo de la enfiteusis ver Infesta (1991).

18-Cfr. Banzato (1998).

19-Escriche (1874, v. 4 p. 337).

20-Archivo Histórico de la Provincia de Buenos Aires, Escribanía Mayor de Gobierno (en adelante AHPBA-EMG), leg. 138, expte., 1106, año, 1804. 
No obstante, casi nadie pedía permiso para asentarse en terrenos baldíos, fundaban primero su estancia en terrenos que consideraban desocupados y luego solicitaban los títulos. Sin embargo, no era suficiente establecerse en los nuevos territorios para asegurar el dominio sobre la propiedad, siendo éstas tierras del Estado el reconocimiento de los vecinos se constituía en un factor determinante a la hora de solicitar los títulos. ${ }^{21}$ Quién ocupaba y cuánto se decidía en función de parámetros muy laxos. Especialmente la disponibilidad de capital y conexiones para colocar los productos en el mercado de Buenos Aires permitieron a unos pocos solicitar parcelas de grandes extensiones, para los demás, el fuerte y el pueblo que se formaba a su alrededor se constituían en el desemboque inmediato de su producción; para todos, las vinculaciones en la red burocrática local y regional eran vitales a la hora de sacar un expediente adelante. En definitiva, en el cruce de estas variables económicas, políticas y sociales quedaban las disputas entre los aspirantes a un terreno.

Aunque las donaciones del Directorio estaban destinadas a nuevos pobladores, su alcance se extendió a aquellos que hacía muchos años estaban poblando en territorio que había sido avanzada española sobre el territorio aborigen y ahora veía alejarse la línea fronteriza. En los trámites de donaciones del Directorio, si bien los solicitantes tuvieron en cuenta primordialmente los servicios al Estado, aunque la antigüedad de población también fue importante como argumento, en 12 de las 30 tramitaciones los ocupantes pudieron certificar más de diez años de asentamiento. Es más, en 13 ocasiones los trámites de moderada composición, antes de concluir en el pago de la tierra, con una nueva solicitud, terminaron en una donación.

Pero aún así, algunos poseedores no alcanzaron a tramitar sus títulos cuando se detuvo la enajenación de tierras públicas en el año 1822 para luego decidir su entrega en enfiteusis. ${ }^{22}$ Para esta época estaba ocupado todo el territorio al norte del río Salado ya fuera en posesión o en propiedad. A partir de 1824, la engorrosa legislación enfitéutica obligó a todos los tenedores de terrenos públicos a solicitarlos en un plazo perentorio de seis meses, luego del cual perderían su derecho de preferencia ${ }_{r}^{23}$ amenaza que al repetirse en 1826 demostró ser muy poco efectiva. ${ }^{24}$

21-Escriche (1874, v. 4, p. 626).

22-Decretos del 17 de abril y $1^{\circ}$ de julio de 1822. REGISTRO OFICIAL DE LA PROVINCIA DE BUENOS AIRES, Buenos Aires, Imprenta del Mercurio, 1874, año 1822, pp. 83 y 117. (En adelante ROBA)

23-Decreto del 28 de setiembre de 1824. ROBA, año 1824, p. 79.

24-Decreto del 15 de abril de 1826. PROVINCIAS UNIDAS DEL RÍO DE LA PLATA. Registro Nacional, año 1826, Buenos Aires, imprenta del Mercurio, 1874, p. 61-62. (En adelante RN) 
Además, uno de los decretos que reglamentaban la enfiteusis impuso la "suerte de estancia" (tres cuartos de legua cuadrada) como mínimo necesario para solicitar las tierras, por debajo de esta 2.025 hectáreas ${ }^{25}$ se consideraban sobras y, aunque tenían la posibilidad de incluir otros terrenos contiguos para completar la medida, si no lo lograban podían ser reclamadas por el lindero que tuviera mayor extensión adyacente al terreno. ${ }^{26}$ Esta disposición trajo serios problemas para aquellos medianos o pequeños poseedores que no habían tramitado los títulos por los sistemas anteriores, puesto que si no alcanzaban las medidas mínimas sus terrenos podían ser disputados por los vecinos. Entre la aplicación de los distintos sistemas de acceso a la propiedad, aunque las solicitudes y entregas de tierras se aceleraron entre 1818 y 1822, iban quedando algunos que por distintos motivos no realizaban los trámites, y cuando los empezaban tenían que lidiar con las pretensiones de otros pobladores.

\section{Reconocimiento de posesión entre viejos y nuevos ocupantes}

En el estudio de los conflictos por la tierra para otras regiones, se ha trabajado el concepto de posesión inmemorial. Por ejemplo, Mariana Canedo ha encontrando que era posible litigar con éxito en Los Arroyos, a partir de la posesión continua del campo durante muchos años. ${ }^{27}$ En Brasil se distinguía entre posesión natural y posesión inmemorial, la primera basada en los actos posesorios, en el hecho mismo de ocupar tierras baldías y producir. Los abogados de los pequeños poseedores legitimaban con este concepto el acceso a la tierra en contra de los grandes fazendeiros quienes optaban por la posesión inmemorial que no necesitaba ser probada por actos de ocupación, sino que bastaban los testimonios que confirmaran el dominio sobre el terreno. ${ }^{28}$ En la región que estudiamos la noción más usada fue antigua posesión, que guarda en su utilización todos los atributos del concepto posesión inmemorial, el cual según la jurisprudencia española requería 40 años continuados en la ocupación del terreno. ${ }^{29} \mathrm{El}$ derecho de primer poblador estaba presente en todos los litigios por tierras y era el que podía en casi todas las ocasiones, sino ganar el juicio, al menos obtener un beneficio importante. Este era, sin dudas, el argumento más fuerte. En los casos que presentamos estaba siempre ligado al acto posesorio, o sea a la ocupación efectiva del territorio levantando un rancho, plan-

25-En adelante has.

26-Decreto del 27 de setiembre de 1824, art. $4^{\circ}$ y $5^{\circ}$. ROBA, año 1824, p. 78-79.

27-Canedo (1996, cap. VI).

28-Menendes Motta (1998).

29-Escriche (1874, v. 4, p. 626). 
tando árboles, armando un corral y poblando con animales o sembrando.

Don Francisco Coz, hacía mucho tiempo que estaba habitando en el pago de Chascomús cuando fue nombrado maestro de postas en $1818 .{ }^{30} \mathrm{Un}$ año estuvo desempeñando el cargo sin cobrar los servicios que le correspondían, cuando don Leonardo Pereyra denunció un terreno adyacente cuya extensión reducía las dimensiones del que se encontraba asentado Coz. Temiendo ser expulsado, a la vez que se reducía su parte a un tamaño que consideraba insignificante y estimando que no le permitiría continuar con su tarea, comunicó el hecho al Administrador General de Correos y la intervención de su superior logró mantenerlo en su establecimiento. En 1820 murió don Francisco Coz, por lo que su hijo Juan Ignacio se hizo cargo de la posta, dos años después surgió un segundo conflicto, esta vez con Ramón Morales quien dijo estar asentado desde 1812 con permiso del antiguo comandante Fermín Rodríguez, planteó que no había podido denunciar antes su terreno y que sus vecinos ya lo habían hecho dejándole media legua cuadrada donde tenía su chacra. Coz argumentó que

"El terreno que ocupa nuestra Poblasion y hasiendas, ha sido constantemente ocupado por nosotros, con tantos años á esta parte; que mi difunto Padre era distinguido con el epiteto de antiguo Poblador; pues lo estaba en aquel lugar desde antes de fundamentarse la Guardia de Chascomus". ${ }^{31}$

Al tiempo que atacó la presentación de Morales manifestando que no eran siete sino sólo tres los años de asentamiento de su oponente, por otro lado, reiteró que era un poseedor de más de treinta años, lo que fue atestiguado por la declaración de dos viejos vecinos ante el juez de paz. ${ }^{32}$ Como la resolución de este pleito fue posterior a la inmovilización de la tierra pública de 1822, el terreno quedó encuadrado en las disposiciones sobre la enfiteusis y tuvo que solicitarlo nuevamente, Coz adujo una vez más la necesidad de contar con un predio mínimo para desempeñarse en el cargo y su condición de antiguo ocupante, nuevamente su trámite se atrasó por no cumplir con las reglamentaciones. Las tribulaciones del maestro de postas no terminaron en la década de 1820, hacia 1838, cuando todavía no estaba resuelta la propiedad legal de su parcela, José Ferrari solicitó comprar un terreno lindero iniciándose un nuevo

30-AHPBA-EMG, leg. 148, expte. 11912, año 1819.

31-Subrayado en el original.

32-Don Juan Andrada y don Gregorio Marín personas de gran reputación en el pago, a quienes se recurría frecuentemente en las solicitudes de tierras para confirmar el antiguo asentamiento de los denunciantes. 
proceso judicial. Su opositor era uno de los principales hacendados de la zona, en 1828 había logrado por compra a particulares integrar una estancia de 17.000 has. $^{33}$ Para mediados de la década de 1830 había parcelado y vendido el lado lindero con el terreno de $\mathrm{Coz}_{1}{ }^{34}$ cuando se realizó la mensura hacia 1838 el agrimensor encontró un sobrante de terreno que Ferrari intentó sumar a su campo argumentando que el predio disputado se encontraba "entre de los mojones antiguos y conocidos que limitaban la propiedad [de Ferrari]", y que

"Es una regla inconcusa, que en materia de enfiteusis, mercedes y compras de terrenos publicos, debe ser preferido el que se encuentra en posecion, siempre que llene las condiciones generales que las leyes prescriben para su enagenacion; y esta regla se ha observado con tanta escrupulosidad en las diversas y multiplicadas providencias que se han dictado, reglamentando este ramo de la administracion fiscal, que no pueden citarse una sola en que se haya contrariado de algun modo. En las que introdujeron á la Provincia el enfiteusis de las tierras públicas, y en todas las que se sancionaron en diversas épocas para llevar al cabo esta institucion, se acordó nominalmente la preferencia al poseedor sobre cualquiera otro denunciante, aunque la posecion fuera sin titulo legal obtenido del gobierno: en las mercedes que se han hecho antes y despues de haberse establecido el enfiteusis, se han salvado tambien los derechos de los poseedores de una manera esplicita y terminante".

Cuando en 1819 don Juan León Negrete tuvo que sacar su hacienda de Quilmes porque se reservaron los terrenos para chacra, le compró a los herederos de un vecino de Ranchos un predio que "posehia [desde] muchos años", una vez aquerenciados los animales, un recién llegado, Fermín Almirón, hizo medir un terreno que tomaba "lo mas y mejor" de las tierras de su lindero. ${ }^{35}$ Negrete protestó por que la mensura de Almirón invadía su posesión, advirtiendo que su rival tenía un asentamiento nuevo en comparación con los años de fundación de la estancia que él estaba usufructuando. Este es un caso típico en que los derechos de ocupación tienen la antigüedad del primer asentamiento, si el primero que habitó no alcanzó a obtener los títulos (recordemos que Negrete había comprado a otros que no los tenían), los que siguen, compran sólo esta prerrogativa para ser tenido en cuenta en caso de que el Estado decida vender la tierra, pues ésta sigue estando en posesión de quien la ocupa,

33-Archivo Histórico de Geodesia, Ministerio de Obras Públicas de la Provincia de Buenos Aires (en adelante AHG), Duplicados de Mensura, partido de Brandsen, número 16.

34-AHG, Duplicados de Mensura, partido de Brandsen, números 16, 64, 71 y 105.

35-AHPBA-EMG, leg. 141, expte. 11470, año 1820. 
pero no en propiedad plena.

Un caso más claro aún en el que la antigua posesión peligra ante las nuevas denuncias es el de don Juan Arriola, emparentado con los López, quienes tenían un siglo de asentamiento en los límites entre Ranchos y Chascomús cuando en 1820 Felipe Chavarría recibió una donación del directorio y empezó a mensurar todo el espacio desde la laguna de Vitel hacia Ranchos. ${ }^{36}$ Arriola, cuestionó que Chavarría traspasara los límites entre los pagos y se preguntaba si no tenía más derecho a la tierra que el nuevo solicitante

“... pues á mas del derecho de posecion ser un vecino afincado y con familia, los inmensos perjuicios que estoy sufriendo ya en mi persona como en donativos para la Patria y contribuciones para la Guardia? Y que será el pago el arrojarme para que venga uno de afuera sin tener no solo una cabeza de ganado ni el mas minimo palo puesto ni haber sufrido los perjuicios como yo he sufrido, y que aun contra la voluntad del mismo Gobierno quiera hecharme y despojarme de lo que con el sudor de mi rostro y honradamente he adquirido para mantener a mi muger e hijos?

Aunque Chavarría había recibido una donación del directorio, Arriola estimaba que debía ser preferido en la obtención del título para comprarlo en moderada composición debido a los cien años de antigüedad en la región que tenía la familia de su esposa, cuestión que también se probó con la declaración de testigos, todos vecinos de larga data, tres de ellos propietarios de tierras..$^{37}$

Hacia 1820 Luciano Gaete, hacendado importante en la campaña, recibió una donación de un terreno en Ranchos, María Cantero se opuso alegando que hacía doce años que lo poseía y por lo tanto tenía derecho de preferencia para compra o donación, pero además su situación personal era evidentemente difícil ya que su esposo había sido sargento en los regimientos de campaña y murió en combate contra los indios, ella había sido salvada recientemente del cautiverio y sus tres hijos permanecían en esta situación luego de las últimas invasiones de los aborígenes. ${ }^{38}$ Si María Cantero puso en juego su evidente desamparo, Gaete contraatacó con un escrito pleno de tecnicismos, muy rico a los

36-AHPBA-EMG, leg. 149, expte. 11935, año 1820.

37-Alegre, vecino lindero al terreno en disputa, estaba en el pago desde 1789 y obtuvo sus títulos en 1821 (AHPBA-EMG, leg. 2, expte. 56, año 1819), Leonardo Piedrabuena, de reconocida trayectoria en el pago, tenía su propiedad al sur del río Salado desde 1809, escrituró en 1819 (AHPBA-EMG, leg. 155, expte. 12251, año 1819), Escribano estaba desde 1811 también al sur del río Salado, en el mismo año 19 consiguió ser propietario (AHPBA-EMG, leg. 149, expte. 11967, año 1819).

38-AHPBA-EMG, leg. 151, expte 12031, año 1821. 
fines de este trabajo pues no solamente evidencia la alta frecuencia de las ventas de derechos de usufructo, sino que también señala los alcances del concepto de posesión y la diferencia entre los poseedores sin títulos de la tierra. Gaete había comprado los derechos a don Francisco Pariente quien poblándolo con ganados había formado una estancia, y "toleró" que su peón José Oroño (marido de María Cantero) construyese un rancho "en el que permanecio sin tener ganado alguno, ni cosa que constituya un regular establecimiento de $\underline{\text { campo }^{\prime \prime}},{ }^{39}$ de manera que, razonaba Gaete, Oroño nunca fue hacendado sino agregado de Pariente así que la viuda del peón no podía alegar ser un tercero perjudicado en la transacción. Por lo tanto, concluía

"La posesión verdaderamente tal, la que da un derecho, cuyo perjuicio puede reclamarse, no es la insistencia corporal de la cosa; por que asi se diria que tenia posesion el inquilino, y el colono. La posesion que el derecho conoce, no solo dice insistencia en la cosa, sino tambien la crehencia que induce al animo del tenedor á persuadirse, que tiene, ó está en lo suyo; y por eso es que la Ley definiendo la posesion, dice que es la tenencia con ayuda del cuerpo, é del entendimiento. Lo demas es detencion, no es posesion, ó será una posesion precaria, que ningun derecho produce".

Aún más, cuando se realizó la mensura el rancho estaba abandonado, así que Gaete siguió en su argumento

"Oroño nunca poseyo el terreno que ocupa su rancho, aunque de hecho lo tenia; y como la posesion natural, ó lo que de hecho solo se tiene, se pierde con el hecho de dexarlo, resulta tambien que aun la tenencia perdio la viuda pues desamparó el rancho".

Aunque Gaete basaba su argumentación en la denuncia de la posesión de Oroño y, la pérdida de los derechos de tenencia, veremos como aún puesto en duda el asentamiento anterior de la viuda de Oroño que también estaba contemplado en el derecho vigente, le alcanzó para obtener una compensación. ${ }^{40}$

En 1824 Luis Gallo solicitó la parcela que cultivaba sobre el río Samborombón. ${ }^{41}$ Emplazada entre la gran estancia de las Mulas y otras de menor magnitud era una angosta franja de 1.700 varas de frente por 15.700 de fondo, o sea 2.001 has. Aunque por una escasa porción de 24 has. no llegaba

39-Subrayado en el original.

40-Escriche (1874, v. 4, pp. 337, 624-625.)

41-AHPBA-EMG, leg. 21, expte. 717, año 1824. 
a la "suerte de estancia", se le indicó al Juez que informara si había otros terrenos para completar el mínimo, lo cual era imposible, como demuestra el croquis 1. En noviembre de 1824, su vecino Eugenio Villanueva inició los trámites para obtenerlo en enfiteusis, ya que tenía el costado lindero más extenso sobre el terreno en cuestión. ${ }^{42}$ Desde su primer pedido Gallo se atuvo al argumento de la antigua posesión, lo repitió constantemente y sobre todo cuando se dio cuenta que la aplicación fría de la norma legal le arrebataba sus tierras

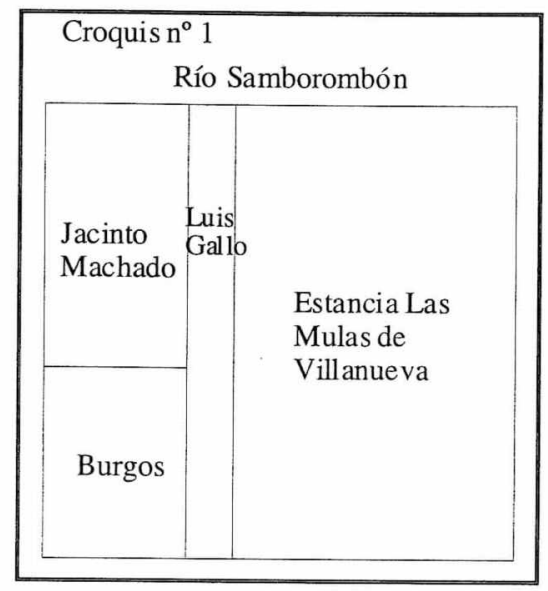

"Así es pues que nosotros con Animales de toda especie en nuestro campo, con Arboledas, con sembrados todos los años, con nuestros Ranchos, y familia hemos vivido sin perjudicar a los colindantes de 20 a 30 años, ... ninguno jamas antes de los reglamentos o decretos desde fines de 1824, ha intentado despojarnos ni disputarnos mejor derecho. Y sobre todo ¿a que corazon, de marmol no le parecerá cruel, y rigoroso desterrar, y desaloxar sin saber donde á unos Padres ancianos con Hijos mayores y menores, con ranchos, sementeras, zanjas, Arboledas y quadrupedos Lanares, Caballares y Bacunos ... por que le falten mil o dos mil baras quadradas...?"

De igual manera Josefa Aguilar, quien ocupaba un terreno sobre las lagunas Encadenadas desde fines del siglo XVIII, no accedió a la propiedad legal con los sistemas anteriores a 1822 y su caso quedó encuadrado en la enfiteusis. ${ }^{43}$ Pero aquí las cosas no estaban tan claras en cuanto a extensión del terreno y 
menos aún respecto al reconocimiento de posesión por parte de los vecinos contiguos. Como muestra el croquis 2 el terreno tenía tres lados apetecibles, (el costado con Quiroga era muy reducido). Uno de ellos limitaba con un propietario de larga data en el partido, pues el padre de Juan Nepomuceno Fernández fue de los primeros, su madre consiguió los títulos por donación del directorio y en año 1824 se lo vendió, ${ }^{44}$ en cambio Tadeo Almada llegó en 1806 y Santisteban hacia el año 1812, ambos también escrituraron mediante una donación. ${ }^{45}$ Tanto Fernández como Almada eran personas de reconocida solvencia -tenían otras estancias al sur del río Salado- y con muy buenas vinculaciones, el primero por la trayectoria militar de su familia, incluidos sus propios servicios; el segundo era suegro de Prudencio Rosas. Doña Josefa tenía como únicos antecedentes su establecimiento temprano hacia el último lustro del siglo XVIII, dos veces viuda y con veinte hijos, cinco de ellos en el servicio militar. Su terreno apenas alcanzaba las 800 has., bien lejos de las 2025 requeridas. ${ }^{46}$ Todos pidieron el predio, aunque sus vecinos reconocían que Josefa Aguilar se había instalado desde hacía mucho tiempo y ninguno podía disputarle mayor antigüedad en el terreno, pues los testigos presentados por todas las partes en conflicto aseveraron los treinta años de asentamiento, de todas maneras trataron de aferrarse a las disposiciones enfitéuticas acerca de la medida mínima para solicitar los campos.

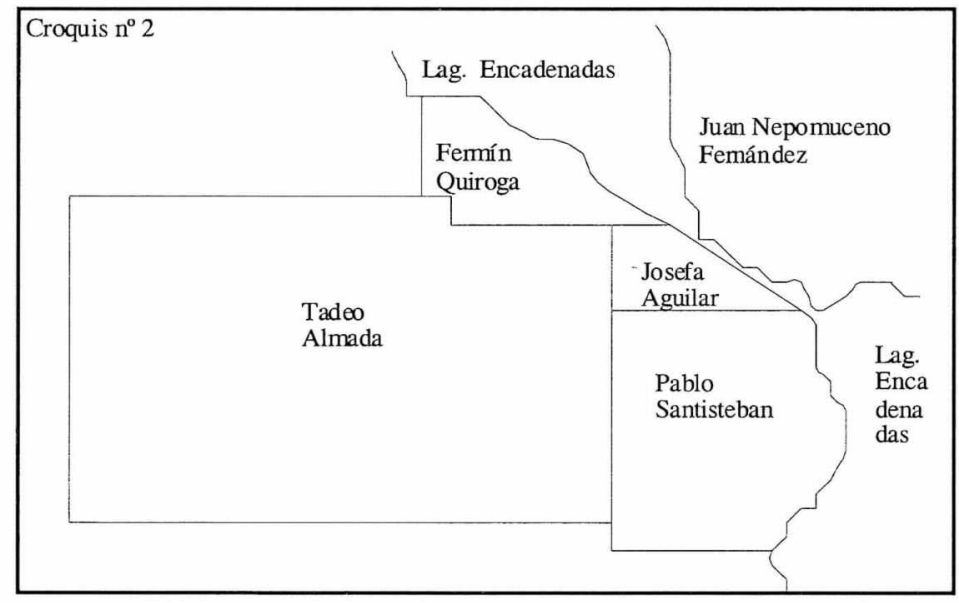

44-AHPBA-EMG, leg. 144, expte. 11642, año 1819.

45-AHPBA-EMG, leg. 142, expte. 11482, año 1819 y leg. 148, expte. 11879, año 1819.

46-De todos modos, tal como el fiscal Pico indicó, estaban tomando el frente sobre el terreno de Almada y el fondo hacia las Encadenadas, aunque no percibieron que éstas, como no corrían paralelas al frente, restaban una buena porción. 
Otro tenor tuvo el interesante conflicto que se originó en Ranchos, entre don Francisco Planes y don Gregorio López. ${ }^{47}$ A mediados de 1816, el primero instaló un puesto y pulpería en los confines de lo que consideraba su estancia, López no solamente se opuso, sino que permitió que "un chacarero" se estableciera en las inmediaciones. Evidentemente López arrendaba sus tierras para agricultura, pues tenía diecisiete "poblaciones", pero a los ojos de su opositor, estos asentamientos indicaban que no los necesitaba para hacienda, de manera que bien podía "donarle" a él aquel pedazo que le servía para salida de su ganado a los manantiales en las épocas de sequía y, a la vez, era la "entrada a los chacareros a robar". Tan insólita solicitud fue fácilmente refutada por López presentando los títulos del terreno, pruebas que su adversario no podía exhibir, pero aún así siguió discutiendo los límites de la estancia de López. ${ }^{48}$

\section{La antigua posesión cuestionada}

Si un vecino era considerado como antiguo poseedor ese reconocimiento determinaba el orden de las mensuras, pero no significaba que estas fueran exactas, sobre todo si se piensa que se hacían con el auxilio de personas del lugar que trabajan de banderilleros con escasa o ninguna experiencia en la tarea, a quienes seguían dos peones llevando una cuerda de entre 86 y 130 metros, todos a caballo galopando sin detenerse pues otros dos marcaban cada medida y recorriendo grandes extensiones en un mismo día. ${ }^{49}$ De manera que tanto la imperfección de las mediciones como el reconocimiento de la comunidad respecto de la antigua posesión provocaban conflictos. El mismo agrimensor podía resolver algunos en el acto de medir, ${ }^{50}$ como la oposición que hizo la viuda de Don Ramón Ibarra a la medición del terreno reclamado por Gallo y Villanueva planteando que se estaban introduciendo en sus campos, la cual fue rechazada por que ya los agrimensores le habían dicho a su marido que, como los vecinos solicitaron las tierras antes que se terminara la medición de la estancia de Las Mulas

47-AHPBA-EMG, leg. 22, expte. 746, año 1816.

48-López había comprado el terreno en 1813 a la testamentaría de don José Roca. AHG, Duplicados de Mensura, partido de General Paz (Ranchos), número 24.

49-En general el informe de las mensuras que hemos consultado se iniciaba con el comentario de la organización del trabajo, que resumió bien en 1828 el ingeniero Narciso Parchappe, para quien este sistema era "grosero", tenía "graves errores" y provocaba "multitud de pleitos que se multiplicaban conforme la división de las propiedades". Cfr. D'Orbigny (1835, cap. XV) traducido y anotado por Grau (1949:391). 50-Ley del 16 de noviembre de 1824. ROBA, año 1824. 
"respetando el derecho solido que esta tenia en su antigua posesión y como de tal se les concedio exponiendose el que quedase dentro cuando se midiese el terreno de las Mulas a sufrir su daño por no haber datos positivos para medir aquellos terrenos hasta que la estancia de Las Mulas aclarase sus lindes"

En otras ocasiones, la presencia de un fuerte hacendado de la campaña podía allanar las dificultades. Por ejemplo, a principios de 1824 Juan Manuel de Rosas representó a Manuel Génova, un primitivo poblador de Ranchos, en la mensura de sus tierras. ${ }^{51}$ Avezado en esas cuestiones, Rosas probablemente calculó que el terreno de su comitente no iba a alcanzar el mínimo indispensable para encuadrarse en las disposiciones enfitéuticas, por lo que en un punto estratégico de la mensura exigió que se continuara midiendo sobre los terrenos de uno de los vecinos que había comprado los derechos de posesión de varios otros, pero aún no los había solicitado al gobierno para obtener la enfiteusis. Es evidente que Rosas conocía muy bien la legislación, puesto que argumentó que tal circunstancia hacía perder el derecho de preferencia, lo que estaba debidamente explicitado en las normas vigentes tal como se ha expresado más arriba. El vecino se avino a lo demandado y acordó ceder una fracción a Génova.

En el caso Coz-Ferrari, éste asociaba la antigua posesión a la estancia y al sobrante, y consideraba que recaía en él debido a que había comprado un terreno cuyos anteriores propietarios se remontaban a fines del siglo XVIII. Si bien se habían realizado mensuras anteriores y la más inmediata databa de 1819,52 sólo en la siguiente medición se encontró que las precedentes eran inexactas y que

"dentro de los límites que ella dio á los terrenos de Ferrari excistia una demasia sobre la estencion de sus titulos, cuyo dominio corresponde al Estado. Sin embargo, el y otro alguno es quien ha ocupado y ocupa esa sobra, á quien por consiguiente competen todos los derechos y prerrogativas de la posesion".

El otro argumento fue que la nueva mensura era deficiente, pues tendría que haber empezado por otro lado. El agrimensor que había medido los campos, (y ahora representaba al maestro de postas), informó que la mensura se había iniciado por el lado convenido entre Ferrari y sus compradores, y se había concluido con el acuerdo de todas las partes. Terminada la medición, surgió el sobrante, del cual, ubicada cada una de las parcelas, Ferrari ya no era lindero 
y por otro lado, no se había quitado un ápice de la cantidad que figuraba en sus escrituras.

No todos los vecinos estaban en su campo al momento de las mensuras, ni todos los agrimensores esperaban la presencia de los vecinos linderos para iniciar su tarea, esto también traía inconvenientes y reclamos porque era una norma que se había seguido en las pretéritas mensuras coloniales y no fue modificada por los procedimientos posteriores. Por ejemplo, Negrete y Arriola adujeron, no solamente que las tierras reputadas baldías tenían dueño, sino también que no se los había citado para la diligencia de mensura, como era obligatorio, y en el caso del primero ni se había contemplado la oposición que hizo su hijo cuando pasaron midiendo a corta distancia de "las casas" ${ }^{53}$

La Comisión Topográfica fue creada en 1824, de manera que recién a partir de esa fecha se pudo comenzar a organizar un registro mínimo de las propiedades rurales, ${ }^{54}$ por lo tanto la delimitación de los nuevos espacios, sobre todo la de aquellos que se encontraban más allá del río Salado, estaba sujeta a la voluntad de las partes y la pericia de los agrimensores. Como los diferentes gobiernos no tenían un aparato burocrático consolidado, sobre todo en los convulsionados primeros quince años después de la Revolución de Mayo, era muy factible que distintas personas denunciaran una misma superficie con muy corta diferencia de tiempo. La ley de enfiteusis, al permitir denunciar las sobras entre terrenos ya enajenados por el Estado también provocó la denuncia de varios solicitantes a la vez, como se ha visto más arriba, aquí sólo ejemplificaremos con un caso paradigmático en que el motivo principal del conflicto fue la doble denuncia de las tierras de Marihuicul, disputadas por el Coronel Pablo José de Eseyza y don Juan Bautista Segismundo. Estamos en presencia de un conflicto entre grandes hacendados de la provincia que residían en la ciudad de Buenos Aires, ${ }^{55}$ y en un periodo muy especial, en que ha comenzado a resentirse el gobierno de las Provincias Unidas del Río de la Plata, con la caída del directorio de Alvear. ${ }^{56}$ Entre el 15 de abril de 1815 luego del levantamiento de Fontezuelas, y hasta el 5 de mayo, el Cabildo de la ciudad de Buenos Aires

53-Las disposiciones incluían expresamente la citación de aquellos que se consideraban con derechos sobre los terrenos contiguos al que se iba a medir.

54-Esteban (1962).

55-Eseyza venía de perder propiedades que las vicisitudes de la guerra en el litoral le habían arrebatado, pero evidentemente le quedó un giro importante. Cfr. Cutolo (1969, v. 2, p. 726). Segismundo, además de haber construido la Recova Vieja en 1803 y de asociarse en el Teatro de Comedias en Buenos Aires, en 1814 había comprado "Los Portugueses", una de las estancias más grandes del hinterland de Buenos Aires con una extensión de 45.890 has.. Cfr. AHPBA-EMG, leg. 148, expte. 11867, año 1825; Garavaglia (1995) y Abad de Santillán (1961:514).

56-Un minucioso análisis puede consultarse en Cánter (1962). 
asumió el gobierno. En ese convulsionado mes de abril, Eseyza solicitó una extensión de 8 leguas con frente al mar por 12 de fondo, unas 260.000 has., que el Cabildo concedió en donación el día 26, tal vez una de las extensiones más grande que se haya otorgado a una misma persona en la época. ${ }^{57}$ Una vez restablecidas las autoridades, el gobernador intendente Oliden ratificó la medida y mandó que se continuara con el trámite de mensura en el mes de agosto. En julio de ese año '15, Segismundo había solicitado unas 65.000 has para una estancia que tenía fundada entre la laguna del maestro Eusebio y los cerros de Bacaloncoy. ${ }^{58}$ En noviembre, cuando el Comandante del Fuerte de Montes Grandes, Ramón Lara, puso en posesión al hijo de Eseyza luego de que se mensurara el terreno, recibió una notificación del agrimensor que iba a medir el de Segismundo y comprobaron que se trataba del mismo espacio. Pese a la oposición de Lara la otra mensura también fue ejecutada. De manera que encontramos una nueva tensión entre las argumentaciones, uno defiende su primer asentamiento y el otro sostiene que denunció antes la tierra. En los casos anteriores se observa que cuanto mayor fuera la antigüedad de la posesión las posibilidades de conseguir que los vecinos apoyaran una declaración se incrementaban, pero en la zona de frontera abierta como el sur del río Salado en los primeros veinte años del siglo XIX, la precedencia en la instalación podía consistir en un par de meses. Segismundo había fundado su establecimiento en las cercanías de la laguna del maestro Eusebio, lo que fue constatado por el agrimensor, quien informó haber visto

"Ranchos, corrales y cerco, todo nuevo, a que acompañaba un rodeo de mas de quatro mil quinientas cavezas ganado bacuno, con su correspondiente cavallada, cuyo dueño era Don Juan Bautista Segismundo, y que Don Pablo Seysa no tenia absolutamente nada".

Los testigos reconocían esos terrenos como propios del solicitante, aunque sabían que Eseyza estaba por mensurar en las inmediaciones, de manera que a Segismundo lo asistía el derecho de tercero perjudicado por la intromisión de la mensura de Eseyza en sus campos y, aunque reconocía que su oponente había denunciado primero, razonaba

"no obstante que la denuncia como he dicho sea posterior por que no tan solo a ella hemos de estar pa deducir el derecho, sino que hemos de atender a la pocecion ó primera poblacion, que aun quando haiga sido 
sin precedente permiso de la authoridad no por eso dexa de llamarse un titulo bastante para disputar la preferencia pues siempre por la misma authoridad se otorga antelacion a los posedores quales quiera que sea el modo de su pocecion".

En la época colonial y hasta 1820 las disposiciones no marcaban una fecha determinada a partir de la cual se perdía el derecho de posesión si no se realizaba el trámite, no obstante Eseyza pudo argumentar que su solicitud era anterior en meses porque siempre había estado claro que, no sólo quien primero se instalaba sino también quien primero denunciaba, si no había un tercero perjudicado, era el preferido a la hora de valorar sus condiciones para acceder al título de propiedad. En cambio con la enfiteusis los plazos empezaron a correr en forma perentoria, por lo tanto, como fueron varias las solicitudes sobre el terreno ocupado por Josefa Aguilar, Juan Nepomuceno Fernández intentó que se tuviera en cuenta el derecho de preferencia como primer denunciante y Ferrari llevó el asunto a su máxima expresión cuando dijo que su solicitud de compra al estado era anterior en veintiséis días a la de su vecino Coz.

Debido a que Chascomús y Ranchos habían nacido como avanzada castrense en la frontera con las tribus aborígenes, buena parte de sus pobladores eran militares de profesión o milicianos, y muchos de ellos se establecieron como productores agropecuarios, aunque no todos alcanzaron la propiedad de los terrenos. Con ese propósito, utilizaron como argumento de su solicitud estos servicios militares prestados al Estado. ${ }^{59}$ De igual manera fue una de las razones fundamentales para aquellos que solicitaron donaciones del directorio entre los años 1818 y $1822 .{ }^{60}$ Este fue el alegato principal de Eseyza para justificar su solicitud, ya que habiendo tenido establecimiento en Entre Ríos sus servicios en el ejército fueron premiados con el cargo de coronel de milicias en reconocimiento de 70.000 pesos que se le debían, pero luego de la "acción del Espinillo" perdió sus documentos y papeles, lo que redujo a su "numerosa familia a una horrorosa desnudes". Declaró que sus pérdidas alcanzaban los cien mil pesos y no podría recuperarlos. Sin dudas la indigencia era una exageración para quien solicitaba una extensión de tierra de gran magnitud, que luego debía poblar con ganado. También Morales argumentó que había prestado servicios al país pues se presentó a las autoridades como sargento retirado de Blandengues a lo que Juan Ignacio $\mathrm{Coz}$ respondió que la antigüedad

59-En otro trabajo hemos expuesto el problema de las promesas de reparto de tierras a los primeros ocupantes en Chascomús, y destacamos la justificación que hicieron los comandantes de la guardia de su doble función de pobladores y milicianos. Banzato (1995).

60-Infesta (1986) y Banzato (1998). 
de los servicios de su padre era superior a la de Morales. ¿Y las mujeres? María Cantero, para que no quedaran dudas de la legitimidad de su solicitud, se presentaba como "viuda del 1er. sargento del Regimiento № 5 de Campaña, José Oroño, que murió en la última invasion de los Indios en servicio del orden"; Josefa Aguilar, como se ha dicho, había auxiliado a la milicia con el más importante de los servicios, le había entregado a cinco de sus hijos.

¿Cuánto ocupar, cuánto solicitar? ¿Qué espacio era el mínimo indispensable? Los autores presentan distintas estimaciones de la época, hemos visto que durante la vigencia de la enfiteusis se había determinado el mínimo de 2.025 has. a otorgar, aunque se encuentran numerosas estancias de menor magnitud. Sin dudas el acceso al agua, el buen drenaje del terreno, la presencia de montes y árboles, además de las posibilidades económicas del ocupante, eran factores a tener en cuenta. ${ }^{61}$ Cuando el espacio elegido se veía amenazado las necesidades mínimas pasaban por la percepción, los cálculos propios de aquel que veía invadido su terreno y presentía que se quedaría sin pastos o que se cortaba su acceso a las aguadas. Ante la ocupación de Morales, Coz planteó que

"en virtud de mi genio pasifico, enemigo de discordias, he tolerado su establecimiento, sin embargo de ser nada adaptable al ensanche, que deve tener la mía para el desempeño de mi cargo"

Cuando no pudo obtener el terreno en enfiteusis volvió a litigar contra su vecino Morales, solicitando que desalojara porque había cargado excesivamente de animales el predio, no había sembrado y estaba preso por carnear ganado ajeno. Asimismo pidió el desalojo de otras dos personas a las que calificó de "intrusos" que traían más animales, consumiendo así mayor cantidad de pasto lo que reducía el disponible para sus haciendas y perjudicaba su buen desempeño como maestro de postas. Esto es, la tolerancia tenía un límite, hasta donde llegaba la abundancia de pastos en el terreno o hasta que el tolerado pretendía constituirse en propietario, como le pasó a la viuda del peón Oroño. Arriola estimaba que la mensura de Chavarría lo había dejado "reducido a una corta y quasi insignificante lonja de tierra, en donde no es posible mantener ni pastorear el Ganado". Como muestra el croquis 2, Tadeo Almada contaba con una estancia más que considerable, 10.660 has., pero no llegaba a las aguadas naturales que proporcionaban las lagunas Encadenadas, así que, aprovechando la posibilidad que le otorgaban los decretos y leyes sobre la enfiteusis, solicitó el terreno de su vecina Josefa Aguilar para ensanchar los suyos y aumentar

61-Todas variables que se tenían en cuenta para la tasación de los campos. Cfr. Banzato y Quinteros (1992). 
la extensión disponible en función del procreo de sus haciendas. Razones parecidas tenía Fernández, quien tenía en propiedad unas 8.400 has., aunque las lagunas separaban de su estancia al predio en cuestión. Por su parte, Josefa Aguilar alegaba que al menos ellos tenían espacio suficiente por más que crecieran sus ganados, mientras que ella sin ese lugar se quedaba sin nada, pues los vecinos que durante años habían visto a sus ganados pastar allí ahora pretendían arrebatárselo.

\section{Desenlace de los litigios}

\section{El amparo como solución transitoria}

Esta era una vía precaria pero útil ante el conflicto, o para prevenirlo, tal como pidió Antonio Nas en 1801

"con la experiencia de otros ejemplares, en que atendidas ellas se ha amparado y mantenido a los poseedores de terrenos que no pertenecen a ningun particular en el interin venga el caso del enunciado arreglo, librandose providencias de amparo ... se digne proveer se me defienda y ampare en mi relacionada posesión bajo los apercibimientos competentes de derecho contra los que me perturben e inquieten, mientras tanto se determine lo que se tenga por conveniente en orden al referido arreglo de los campos".

Habiendo accedido el fiscal, aunque aclaró que la posesión no le daba derecho de preferencia, Nas se mantuvo en esta condición hasta su muerte y su hija Laureana logró los títulos de propiedad en $1819 .{ }^{62}$ En el caso de Coz, la intervención del Administrador General de Correos logró que se ordenara dejar libre el espacio necesario para el funcionamiento de la posta, una vez medidos los terrenos de Pereyra obtuvo un nuevo amparo hasta que una mensura general delimitara cuánto podía tomar pues el tamaño del predio no alcanzó para solicitarlo en enfiteusis. Almirón fue declarado "en rebeldía" por no contestar las presentaciones de Negrete, y este quedó amparado en su propiedad, precaria por cierto, hasta la sanción de la ley de enfiteusis. Este amparo y la ocupación permanente fueron suficientes para mantener la posesión pues ni siquiera por esta norma obtuvo los títulos, ya que sus herederos terminaron comprándoselo al Estado, ya dividido, en la década de 1850. 


\section{Convenios entre las partes}

En el caso Coz-Morales, éste dio un poder a Juan Lorenzo Castro, ex Alcalde de la Hermandad de Chascomús y ducho en esos menesteres, para que siguiera las actuaciones. Evidentemente la jugada fue exitosa porque las partes firmaron un acuerdo extra judicial para dividir las 1.350 has. que les habían otorgado, cediendo Coz diez has. para agricultura aunque como se ha dicho tenía un amparo a su favor. Este convenio favoreció a Morales pero quedó anulado en la práctica cuando fue a prisión y su vecino hizo el pedido de enfiteusis.

Estos arreglos, además de solucionar rápidamente la cuestión planteada, ahorraban gastos a los contendientes, como lo manifestaron Arriola y Chavarría quienes hicieron un acuerdo "con el objeto de cortar un litigio que nos fuese costoso á ambos", en el que Chavarría, que había llegado después al terreno, le cedía a Arriola "mil quinientas varas de frente con todo el fondo mensurado en el costado del Norueste de dicho terreno", con la condición de que trasladara a esa parte su establecimiento y el de sus parientes.

El gobernador mandó desalojar a Francisco Planes de las tierras de López, pero el primero logró salvar su situación con un acuerdo muy conveniente a sus intereses, en el que desistía de cuestionar el derecho que tenía Gregorio López al terreno, y éste se comprometía a ordenar que se trasladaran los puestos que estaban cerca de la pulpería de Planes, la que podría permanecer en sus terrenos "en obsequio de la armonia, y sin perjuicio de tercero", lo que efectivamente se realizó. Muy parecido fue el acuerdo extrajudicial en el que Eseyza aceptaba que Segismundo había poblado primero las tierras de Bacaloncoy y éste reconocía que su oponente tenía derechos suficientes sobre el resto de las tierras que le había otorgado el Cabildo, a pesar de que se estableció una interesante discusión acerca de la legitimidad de la donación debido a que tanto Segismundo como el fiscal actuante no admitían que el Cabildo tuviera autoridad suficiente para enajenar tierras del Estado. En el caso entre María Cantero y Luciano Gaete, cuando el fiscal indicó que debía ponerse la causa a prueba firmaron un acuerdo en el que ambos renunciaban a los derechos que pudieran tener sobre el terreno y los cedían a favor de Don José Valentín García, recibiendo doña María "un valor equivalente", de manera que ninguno de los oponentes logró forzar al otro a reconocer algún tipo de derechos, pero quien estaba asentada en el terreno fue indemnizada, aunque su antigua posesión estaba cuestionada.

\section{Dictamen de las autoridades}

El agrimensor representante de Coz argumentó que podía integrarse la extensión al terreno de $\mathrm{Coz}$ a fin de que pudiera comprarlo completo al Estado, 
en primer lugar porque el amparo que había recibido se basaba en su antiguo asentamiento y en los servicios prestados al Estado, y a su vez indicaba explícitamente que debía completar su terreno con otros baldíos que hubiese linderos; pero además porque había tenido un segundo amparo hasta la mensura de las tierras, en vistas de que no había "perjuicio de tercero". Con la anuencia del fiscal que hizo suyos los argumentos del agrimensor, Coz ganó el juicio, pudo completar las medidas mínimas solicitadas y comprar.

En los casos de terrenos declarados sobrantes las autoridades no sentaron jurisprudencia en sus fallos. Sobre los mismos argumentos hubo fiscales que aplicaron la ley tal como estaba escrita y otros que tuvieron en cuenta las circunstancias que rodeaban al caso. No hubo posibilidades para Luis Gallo, en 1826 el fiscal Acosta indicó que habiendo dos denuncias debía primero resolverse el derecho de preferencia, sin mención alguna de los derechos de las partes. Aquí concluye el expediente iniciado por Gallo, aunque a partir de la solicitud de Villanueba podemos suponer que desistió de su oposición porque cuando se mensuró en diciembre y se dio la posesión, Gallo estaba presente junto a otro ocupante, ambos aceptaron desalojar cuando se los solicitó el nuevo propietario. ${ }^{63}$ En cambio en el caso de Manuel Génova, aún con el agregado de terreno solicitado por Rosas, la Comisión Topográfica observó que no alcanzaba a una suerte de estancia, pero debido a que la cantidad era ínfima, y a que el solicitante había prestado servicios al Estado podía aprobarse y mandar que se incorporara la parte del terreno que faltaba sacándola otra vez del vecino que no había hecho todavía los trámites de enfiteusis. Génova obtuvo el terreno en enfiteusis en 1825 y su viuda lo compró alcanzando la propiedad plena en 1838, cincuenta y cuatro años después de que el marido fundara la estancia.

Tal vez el caso en que todos los argumentos se confrontan es el de Josefa Aguilar, quien tuvo no sólo el apoyo del fiscal Pico, sino también de la Comisión Topográfica. Según aconsejaron los expertos de esta última, si se atenían a la forma en que estaban mensurados todos los campos y al espíritu de lo reglado últimamente, ${ }^{64}$ Juan N. Fernández no podía alegar derechos porque las lagunas dividían los dos campos y ninguno de los predios similares cruzaban de un lado a otro de la divisoria de aguas; en cambio si tomaban en cuenta el mínimo indispensable que marcaba la ley y el campo no alcanzaba a las 2.025 has., debía dirimirse entre los linderos de mayor extensión Fernández y

63-Esta parcela, que se había fusionado a la estancia de Las Mulas, luego fue comprada al Estado por Villanueba.

64-Decreto del 6 de julio de 1826, art. 1. RN, año 1826, p. 118. 
Ford-Baudrix; ${ }^{65}$ por último, si el terreno alcanzaba la medida se haría valer la antigüedad de asentamiento de la ocupante. Sabemos ya que luego de la mensura las cosas estuvieron más claras, los expertos coincidieron en que no alcanzaba, aunque como se ha explicado indicaron que faltaba poco, pero que igualmente podía tenerse en cuenta que en otros casos se había otorgado igual la enfiteusis, que el terreno lindaba con aguadas permanentes y que la ocupante hacía muchos años que estaba allí. A estas consideraciones el fiscal agregó los principios de no otorgar grandes extensiones "para alexar los subarriendos o feudatarios" y de dar preferencia al poseedor. Pico argumentó que todos los linderos tenían suficiente terreno y aunque la razón principal que alegaron fue que el de su vecina no alcanzaba la suerte de estancia, la señora en cuestión tenía una antigüedad de 30 años, habían muerto allí sus dos esposos, sus hijos estaban sirviendo en la milicia y aún ella permanecía en el campo con sus ganados, por lo que se preguntaba

"iy habia razon para arruinar a una viuda infeliz que ha dado tantos brazos a la Patria por solo la mezquina idea de que falta a su posesión una pequeña parte para complementar suerte de estancia? ¿No es atendible su posesión de 29 años y triste el recuerdo de desalojarla con sus hijos del lugar de su nacimiento a buscar otro asilo? Ultimamente ¿No es injusto el exponerla a que pierda sus ganados sacandolos de su antiguada querencia y que por no sufrir tal quebranto tenga que malvaratarlos a los vecinos colindantes a que sin duda tendran aspiraciones? Lo es Señor Exelentisimo"

Por lo tanto, aconsejó que se diera el terreno a Josefa Aguilar. Ford y Baudrix contestaron esta exposición solicitando que se atuviera al texto expreso de la ley, esto es, medidas mínimas y mejor derecho para los linderos que lo solicitaran. El Fiscal volvió sobre sus argumentos referentes al servicio que los hijos de Josefa Aguilar hacían al Estado, la antigua posesión y ahora un argumento que no había aparecido en ninguno de los litigios anteriores, su condición de nacidos en el país acosados por dos extranjeros

" ¿Y quienes S.E. pretenden que V.E. reboque su providencia, y destruya una familia venemerita natural del pais? Precisamente dos individuos que no son naturales de el y precisamente los que no tienen el mejor derecho",

65-Estos habían comprado la estancia de Tadeo Almada y en la escritura se incluyó el derecho a la solicitud de enfiteusis. 
porque no tenían el lado más extenso sobre el terreno solicitado, y agregó que el conjunto de los argumentos planteados significaban una interpretación de la ley y una forma de buscar equidad para no beneficiar a los "ambiciosos" que tenían terrenos de sobra, perjudicando a una "honrada familia". En el año 1834, doña Josefa, que se había casado por tercera vez, recibió el predio en enfiteusis y lo compro al Estado en $1837 .{ }^{66}$

\section{Conclusiones}

El análisis de los conflictos en torno a la ocupación del territorio y los derechos que devienen de la misma, en la transición del régimen colonial al período rosista, ha permitido reconocer los motivos de las disputas, las argumentaciones que sustentaban quienes sentían avasallados sus derechos, y apreciar el rol de las autoridades. Entre las causas que originan los litigios se ha examinado la importancia del reconocimiento de los vecinos del lugar para dar el paso de poseedor a propietario, los problemas en el trámite y trazado de las mensuras y las denuncias sobre un mismo terreno. En cuanto a los fundamentos que esgrimían los contendientes se destacan la anticipación en la denuncia, los servicios militares al Estado, la percepción de que el espacio propio había sido limitado por el oponente y no alcanzaría para organizar una estancia y, por último, la antigüedad del asentamiento. La resolución de los litigios ofrecía varias alternativas, desde la precariedad del amparo, pasando por el arreglo extrajudicial entre las partes, hasta el dictamen final de las autoridades en los casos extremos en que la conciliación se tornaba imposible.

Motivos y argumentaciones se entrelazan, se contraponen, unas veces se complementan y otras se establecen jerarquías. En medio, la tensión entre remotas costumbres reconocidas por el aparato legal colonial y las nuevas normas dictadas por los gobiernos independientes. El carácter de vecino antiguo del pago en conjunción con el establecimiento primitivo en el territorio, reconocido por las leyes de Indias como condición indispensable para poseer el terreno, ser preferido en el traspaso de dominio y convertirse en propietario, fue puesto en duda por la presión de los nuevos poseedores de terrenos, sobre todo en el período de la enfiteusis. Evidentemente la disponibilidad de capital para poner en funcionamiento una estancia podía limitar a su mínima expresión el tamaño del predio lindero, aún cuando este vecino pudiera demostrar antelación en la ocupación efectiva del terreno.

Pero también hay otra tensión importante, entre el que se asienta primero y

66- AHG, Duplicados de Mensura, partido de Chascomús, número 198. 
el que pide antes el terreno, en la mayoría de los casos quien demuestra antigua posesión puede lograr un considerable beneficio, como Segismundo que logró mantener las dimensiones de su estancia, el antiguo asentamiento de Coz prevaleció sobre la anticipación de la denuncia de Ferrari y el caso paradigmático de Josefa Aguilar cuyo antiguo asentamiento no pudo ser derrotado por las pretensiones legalistas de Fernández que apeló también a su denuncia anticipada.

Los servicios militares al Estado fueron útiles cuando no hubo litigios porque había un reconocimiento local del solicitante, así lograron escriturar sus tierras muchas familias de militares de Chascomús y Ranchos, en esta conjunción se basó el fiscal Pico para dar preferencia a la solicitud de Josefa Aguilar quien podía demostrar mucho tiempo en el campo, muchos hijos dados a la patria, varios de ellos en el ejército. No le alcanzó a María Cantero la muerte en servicio de su esposo, porque su misma posesión estaba en duda, aunque fue resarcida en dinero. La participación militar de Eseyza le permitió lograr la propiedad de un descomunal territorio, pero no fue suficiente ante la antigua posesión de Segismundo, por más que en este caso la "antigüedad" se limitara a la instalación de la estancia algunos meses antes.

En cuanto a la resolución de los conflictos se aprecia que el amparo, aunque precario, podía dar suficiente testimonio de posesión para lograr más adelante la propiedad. Tal es el caso de Nas, quien se anticipó a un posible litigio y su hija logró los títulos a posteriori. Más claramente, Negrete fue mantenido en la posesión del predio aún sin otro trámite que el amparo, que lo mantuvo como poseedor inclusive durante la dura legislación enfitéutica. Los Coz fueron amparados en dos oportunidades, al padre para que pudiera mantenerse en el territorio y al hijo hasta que se midieran todas las estancias y pudiera comprobarse que podía sumar espacio a su terreno y pedirlo en enfiteusis. En todos los casos el amparo fue dado a personas que tenían un reconocimiento de vecino y antiguo poseedor. Los acuerdos extrajudiciales fueron numerosos, ya que posibilitaban una resolución rápida y menos costosa de los conflictos, a la vez que equilibraban las posiciones. María Cantero, litigando contra un importante hacendado sostuvo su antigua posesión atacada por Gaete, acordó dejar el terreno que habitaba pero obtuvo una compensación monetaria; mientras Planes consiguió establecer su pulpería en los terrenos de López y éste logró que sus títulos fueran reconocidos por su oponente. La legitimidad de los títulos de Eseyza fue puesta en duda por su adversario y por el fiscal de la causa, el acuerdo extrajudicial le permitió acallar las sospechas y a Segismundo le garantizó el respeto de su antigua posesión y de los límites señalados por su mensura. Finalmente, el dictamen de las autoridades más allá de los amparos, más 
numerosos hasta 1822, puede apreciarse en la época de la enfiteusis cuando hubo oportunidades en que se rigieron por la letra fría de la nueva normativa que se impuso al antiguo asentamiento, como en el caso de Gallo quien no pudo evitar ser desalojado; y en otras ocasiones estiraron los límites de la ley para que se adaptara a los límites del predio solicitado, claro que amparados en la antigua legislación y su reconocimiento al primer poseedor, como en el caso de Josefa Aguilar. De igual manera Coz fue beneficiado por la disposición de las autoridades a evitar conflictos, respetar las normas vigentes y apoyarse en las antiguas leyes.

De esta manera hemos revisado algunas de las cuestiones que rodean a la ocupación de la tierra y acceso a los títulos en la frontera bonaerense, demostrando que la antigua posesión, basada en la legislación colonial, mantuvo su vigencia durante el período independiente, cuando nuevas disposiciones modificaron los requisitos para otorgar las tierras públicas. Si Raúl Fradkin había mostrado la permanencia de prácticas consuetudinarias a lo largo del siglo, en lo atinente a la ocupación y acceso a los títulos sobre los campos, la costumbre también tuvo un "rol decisivo", mientras se consolidaba el derecho de propiedad.

\section{Resúmen}

\section{De ocupantes a propietarios, los conflictos entre vecinos de la frontera bonaerense. Chascomús y Ranchos, 1800-1840}

En este trabajo se estudian los conflictos entre vecinos desde los últimos años del período colonial hasta la finalización de la aplicación de la enfiteusis en la década de 1840, cuando la posesión de hecho sobre un terreno estaba en vías de convertirse en propiedad plena, cada vez que se accedía a los títulos mediante los distintos sistemas de otorgamiento de tierras públicas. Se focaliza la atención en la ocupación del territorio y los derechos adquiridos en los partidos de Chascomús y Ranchos. A partir del análisis de los litigios se aprecia el juego de intereses de los hacendados y las conexiones con el poder civil en la frontera que se definen en la resolución extrajudicial del conflicto. Por otro lado se examina el rol de las autoridades y los fundamentos de los dictámenes. Se revisan los motivos de los conflictos y los razonamientos que expusieron las partes que, en conjunto, ilustran acerca de la utilización de la legislación y la permanencia de normas consuetudinarias, por lo tanto se demuestra cómo la antigua posesión estuvo cada vez más comprometida como figura jurídica precaria, a medida que las nuevas leyes y decretos fueron condicionando la adjudicación de títulos de tierras públicas, especialmente los relacionados con la enfiteusis, aunque mantuvo durante todo el período una importancia fundamental. 


\section{Palabras claves}

- Ocupación - Propiedad Legal - Conflictos - Antiguo Asentamiento -

\section{Abstract}

\section{On occupants and owners. Conflicts among neighbors in the Buenos Aires frontier. Chascomús and Ranchos, 1800-1840}

In this paper, conflicts among neighbors since the last days of the colonial period up to the end of the use of enfiteusis in the 1840 are studied, when de facto posession over a plot was on the way to become full property, whenever title deeds could be got by means of different sistems for the awarding of public fields. Attention is focused on territory occupation and rights acquired in Chascomús and Ranchos districts. From the analysis of lawsuits, the hacendados' [cattle-dealers] plays of interests can be appreciated, as well as their conections with the civil power in the frontier, that are defined in the extra-judicial solution of the conflict. Besides, the role of authorities and the judgment's grounds are examined. We examine the reasons for the conflicts and the arguments posed the partes, which, as a whole, shed light as regards the use of legislation and the permanency of consuetudinary norms. It is therefore demonstrated how the old possesion was everytime more compromised as a precarious judicial figure, as new laws and decrees were conditioning the awarding of title deeds to public lands, especially those related with enfiteusis, though it held a great importance, during the whole period.

\section{Key words}

- Occupation - Legal Property - Conflicts - Old settlement -

\section{Referencias Bibliográficas}

*ABAD de SANTILLAN, Diego (1961). Gran enciclopedia argentina, Buenos Aires, Ediar.

*AZCUY AMEGHINO, Eduardo (1995). El latifundio y la gran propiedad colonial rioplatense, Buenos Aires, García Cambeiro.

*BANZATO, Guillermo (1995). "Los conflictos por la ocupación de la tierra en la frontera bonaerense. Chascomús, 179-1822", V Jornadas Interescuelas / Departamentos de Historia y I Jornadas Rioplatenses Universitarias de Historia, Montevideo.

*BANZATO, Guillermo (1998). “Ocupantes y propietarios legales en la región noreste del río Salado. Chascomús, Ranchos y Monte entre 1779 y 1850”. En: 
*GIRBAL-BLACHA, Noemí y Marta VALENCIA. Agro, tierra y política. Debates sobre la historia rural de Argentina y Brasil, La Plata, EUNLP, pp. 37-64.

*BANZATO, Guillermo y Guillermo QUINTEROS (1992). "La ocupación de la tierra en la frontera bonaerense. El caso de Chascomús, 1779-1821". En: Estudios/investigaciones, La Plata, Facultad de Humanidades y Ciencias de la Educación, n 11, pp. 37-76.

*BARBA, Fernando Enrique (1995). Frontera ganadera y guerra con el indio durante el siglo XVIII, La Plata, UNLP.

*CANEDO, Mariana (1996). La tierra y la población en un área de temprana colonización. El partido de los Arroyos, 1600-1850. Tesis de doctorado, Universidad de Buenos Aires.

*CANTER, Juan (1962). "La revolución de abril de 1815 y la organización del nuevo Directorio". En: LEVENE, Ricardo (dir.) Historia de la Nación Argentina, Buenos Aires, El Ateneo, v. 6, primera sección, cap. II, pp. 203-244. *CUTOLO, Vicente Osvaldo (1969). Nuevo diccionario biográfico argentino (1750-1930), Buenos Aires, Elche.

*D'ORBIGNY, Alcide (1835). Voyage dans l'Amerique Méridionale, París, Pitois-Levrault et Co.

*ESCRICHE, Joaquín (1874). Diccionario razonado de legislación y jurisprudencia, Madrid, Imprenta de Eduardo Cuesta.

*ESTEBAN, Francisco (1962). El Departamento Topográfico de la Provincia de Buenos Aires, Buenos Aires, edición del autor.

*FRADKIN, Raúl (1997). "Entre la ley y la práctica: la costumbre en la campaña bonaerense de la primera mitad del siglo XIX". En: Anuario IEHS, n⿳0 12, pp. 141-156.

*GARAVAGLIA, Juan Carlos y José Luis MORENO (comp.) (1993). Población, sociedad, familia y migraciones en el espacio rioplatense. Siglos XVIII y XIX, Buenos Aires, Cántaro.

*GARAVAGLIA, Juan Carlos (1995). "Tres estancias del sur bonaerense en un período de 'transición' (1790-1834)”. En: BJERG, Mónica y Andrea REGUERA (comp.) Problemas de la historia agraria, Tandil, IEHS, pp. 79-124.

*GARAVAGLIA, Juan Carlos (1995). Poder, conflicto y relaciones sociales. El Río de la Plata, XVIII-XIX, Rosario, Homo Sapiens.

*GONZÁLEZ BERNALDO, Pilar (1987). "El levantamiento de 1829: el imaginario social y sus implicaciones políticas en un conflicto rural". En: Anuario IEHS, $\mathrm{n}^{\circ}$ 2, pp. 137-176.

*GRAU, Carlos A. (1949). El fuerte 25 de Mayo en Cruz de Guerra, La Plata, Archivo Histórico de la Provincia de Buenos Aires. 
*INFESTA, María Elena (1986). "Aportes para el estudio del poblamiento en la frontera del Salado". En: ARCHIVO HISTÓRICO DE LA PROVINCIA DE BUENOS AIRES. Estudios sobre la Provincia de Buenos Aires, La Plata.

*INFESTA, María Elena (1991). Usufructo y apropiación de tierras públicas. Buenos Aires, 1820-1850. Tesis de Doctorado, Facultad de Humanidades y Ciencias de la Educación, UNLP.

*MARFANY, Roberto (1961). "Frontera con los indios en el Sud y fundación de pueblos". En: LEVENE, Ricardo (dir). Historia de la Nación Argentina, Buenos Aires, El Ateneo, tercera edición, v. IV, primera sección, primera parte, pp. 265289.

*MARILUZ URQUIJO, José M. (1978). EI régimen de la tierra en el derecho indiano, Buenos Aires, Perrot, segunda edición aumentada.

*MAYO Carlos, Silvia MALLO y Osvaldo BARRENECHE (1989). "Plebe urbana y justicia colonial: las fuentes judiciales. Notas para su manejo metodológico". En: Estudios/Investigaciones, La Plata, Facultad de Humanidades y Ciencias de la Educación, , $\mathrm{n}^{\circ} 1$, pp. 47-53.

* MAYO, Carlos y Amalia LATRUBESSE (1998). Terratenientes, soldados y cautivos. La frontera, 1736-1815, Buenos Aires, Biblos.

*MENENDES MOTTA, Márcia Maria (1998). Nas fronteiras do poder: conflitos e direito à terra no Brasil do século XIX. Río de Janeiro, Vício de Leitura I Arquivo Público do Estado do Río de Janeiro.

*SALVATORE, Ricardo (1992). "Reclutamiento militar, disciplinamiento y proletarización en la era de Rosas". En: Boletín del Instituto de Historia Argentina y Americana "Dr. Emilio Ravignani”, 3ra serie, $\mathrm{n}^{\circ} 5$.

*SALVATORE, Ricardo (1993). "El mercado de trabajo en la campaña bonaerense (1820-1860). Ocho inferencias a partir de narrativas militares". En: BONAUDO, Marta y PUCCIARELLI, Alfredo, La problemática agraria. Nuevas aproximaciones, Buenos Aires, CEAL, t. 1, pp. 59-92. 